\title{
IDENTIFIKASI JALUR PEMASARAN SAPI BALI DI PASAR TERNAK TRADISINAL
}

\author{
Identification of Bali Cattle Marketing in the Traditional Market \\ ${ }^{1}$ Jeflan Halidu, ${ }^{2}$ Fahrul Iham, dan ${ }^{* 3}$ Yanti Saleh \\ 1Jurusan Peternakan Fakultas Pertanian Universitas Negeri Gorontalo \\ ${ }^{2}$ Fakultas Peternakan Universitas Brawijaya, Malang \\ ${ }^{3}$ Fakultas Pertanian Universitas Negeri Gorontalo \\ *Coresponding Authors: email: yyantisaleh@yahoo.co.id
}

\begin{abstract}
This study aims to analyze the marketing channels and marketing margins of Bali Cows in traditional markets. This research was conducted from April to December 2019. A qualitative descriptive method was used in this research. Primary data collection through surveys based on interviews and observations at the respondent level, and secondary data obtained from relevant stakeholders. The results showed that there are 3 channels, namely Channel I, namely Farmer-Consumer (P-PL-K), Channel II are Farmer - Local Trader - Consumer (P-PL-K), and Channel III are: Farmer- merchant collector - Trader retailer-Consumer (P-PP-Pp-K). The marketing margins for breeders, collectors and retailers are: Rp. 0., Rp. 1,000,000 and Rp. 500,000
\end{abstract}

Keywords: Analysis, Bali Cattle, Marketing

\begin{abstract}
ABSTRAK
Penelitian ini bertujuan untuk menganalisis saluran pemasaran dan margin pemasaran Sapi Bali di pasar tradisional. Penelitian ini dilaksanakan pada bulan April sampai Desember 2019. Metode deskriptif kualitatif digunakan dalam penelitian ini. Pengumpulan data primer melalui survei berdasarkan wawancara dan observasi di tingkat responden, dan data sekunder diperoleh dari pemangku kepentingan terkait. Hasil penelitian menunjukkan bahwa terdapat 3 saluran yaitu Saluran I yaitu Petani-Konsumen (P-PL-K), Saluran II adalah Peternak - Pedagang Lokal - Konsumen (P-PL-K), dan Saluran III adalah: Peternak-Pedagang pengumpul-Pedagang pengecer. -Konsumen (PPP-Pp-K). Margin pemasaran peternak, pengumpul dan pengecer sebesar Rp. 0., Rp. 1.000 .000 dan Rp. 500.000.
\end{abstract}

Kata Kunci: Analisis, Pemasaran, Sapi Bali. 


\section{PENDAHULUAN}

Pengembangan sector peternakan, secara operasional diawali dengan penataan kawasan melalui pendekatan sistem dan usaha agribisnis. Pembangunan kawasan agribisnis berbasis peternakan merupakan salah satu alternatif program terobosan yang diharapkan dapat menjawab pembangunan peternakan yang berorientasi meningkatkan pendapatan dan kesejahteraan masyarakat (Mandaka dan Hutagaol, 2005)., walaupun selama ini sector agribisnis domestic selama ini relative lambat perkembangannya dan rendah produktivitasnya, tetapi masih memberikan ekspor bersih yang cukup besar serta menunjukkan kenaikan dari tahun ketahun (Saragih, 2008),. Hal ini menunjukkan bahwa sector agribisnis memberikan angin segar bagi petani. Perubahan pola piker berorientasi pasar sangat pentingf dilakukan, dalam meningkatkan pendapatan.

Peternakan sapi di Bali merupakan peternakan rakyat, tetapi tujuan utamanya adalah memperoleh pendapatan., namun dalam teknis pemeliharaannya, sebagian besar bersifat tradisional, walaupun ada sebagian kecil bersifat semi tradisional.

Hasil penelitian Sukanata (2010), menjelaskan bahwa semua responden yang di survey menyatakan bahwa alasan utama memelihara sapi adalah untuk meningkatkan pendapatan keluarga, dengan memanfaatkan hijauan atau limbah pertanian lainnya yang merupakan hasil sampingan dari sawah, kebun atau tegalan. Untuk mencapai tujuan tersebut, beternak sapi tidak hanya fokus pada teknis produksi, melainkan harus memperhatikan aspek pemasaran. Sistem pemasaran yang efisien dapat memotivasi peternak dalam meningkatkan usaha, sehingga produktivitas dapat ditingkatkan.

Kecamatan Bongomeme adalah wilayah administratif dari Kabupaten Gorontalo, Potensial ternak sapi potong di wilayah ini sebesar 6490 ekor, dan memiliki pasar ternak tradisional. Aktifitas penjualan ternak sebesar 10-20 ekor/minggu. (BPS, 2018).

Pemasaran sapi potong oleh peternak yang ada di Pasar trasisdional Bongomeme cukup tinggi, hal ini terlihat dari sapi potong (Sapi Bali) yang cukup banyak tersedia dengan harga terjangkau. Untuk menciptakan pemasaran sapi potong yaitu peternak menggunakan saluran pemasaran sapi yang dilalui pedagang pemotong sampai ketangan konsumen itu sendiri. Setiap minggunya banyak peternak, pedagang ternak yang bertransaksi ternak sapi potong di Pasar Bongomeme Transaksi yang terjadi berupa tunai langsung, kontrak pembelian selam proses pasar berlangsung. Kondis ini menarik untuk mengetahui proses, jalur pemasaran yang terjadi di pasar ternak, peran lembaga pemasaran, nilai efisien dari pemasaran yang terbentuk, dan memungkinkan adanya pengaruh karakteristik lembaga pemasaran. Pasar ternak di Kecamatan Bongomeme Kab. Gorontalo dapat dijadikan gambaran ini merupakan case studi dalam pemasaran ternak

Menurut Daniel, (2002); Sudiyono (2004) proses penyaluran barang atau jasa dari produsen ke konsumen akhir, yang dilaksanakan oleh lembaga atau badan badan yang bertugas melaksanakan fungsi pemasaran., sehingga memberikan marjin yang berbeda disetiap lembaga pemasaran yang pada akhirnya membentuk saluran pemasaran., sedangkan Soekartawi (2007) menyatakan bahwa, keuntungan adalah selisih antara penerimaan total dan biayabiaya. Biaya ini dalam banyak kenyataan, dapat diklasifikasikan menjadi dua yaitu biaya tetap (seperti sewa tanah, pembelian alat) dan biaya tidak tetap (seperti biaya transportasi, upah tenaga kerja). Penelitian ini bertujuan menganalisis jalur pemasaran dan besarnya marjin pemasaran Sapi Bali di Pasar Tradisional

\section{METODE PENELITIAN}

Penelitian ini telah dilaksanakan di pasar tradisional Bongomeme, Kabupaten Gorontalo, Gorontalo. Jenis penelitian ini adalah penelitian deskriptif yaitu dengan 
menggambarkan dan mendeskripsikan tentang karateristik lembaga, margin dan saluran pemasaran sapi bali yang berada di pasar ternak tradisional Bongomeme. Penelitian ini dilaksanakan selama 2 bulan yaitu pada April - Mei 2019). Sebanyak 56 responden yang terdiri dari: peternak 14 responden, pedagang pengumpul 22 responden, dan pedagang pengecer 20 responden. Penentuan responden peternak, pedagang dan lembaga terkait dilakukan secara sampling rujukan berantai atau (snowball), mengikuti saran Daymon dan Holloway, (2008).
Informasi awal didapat dari pedagang yang memasarkan ternak sapi di dipasar tradisional Bongomeme. Informasi ini ditelusuri asal ternak didapatkan dan kemana dia menjual ternak tersebut.

\section{Analisis Data}

Analisis uang didigunakan adalah analisis deskriptif untuk saluran pemasaran setiap lembaga penyaluran ternak, sedangkan untuk analisis marjin pemasaran mengikuuti saran Dermawan, (2018); Yapanto, dkk (2020); Lasaharu, dkk (2020) menggunakan rumus:

$$
\mathrm{MP}=\mathrm{Pr}-\mathrm{Pf}
$$

Dimana:

MP : Marjin Pemasaran (Rp.Kg)

$\operatorname{Pr}:$ Harga di tingkat konsumen $(\mathrm{Rp} / \mathrm{Kg})$

Pf : Harga ditingkat produsen $(\mathrm{Rp} / \mathrm{Kg})$

\section{HASIL DAN PEMBAHASAN Karakteristik Peternak}

Responden penelitian yang dimaksud adalah peternak, pedagang Pengumpul, pedagang pengecer. Keadaan umum responden dapat dilihat dari umur, tingkat pendidikan, dan lama usaha menjual ternak sapi Bali. Peternak sebagai pengelola, merupakan factor penentu dalam mencapai keberhasilan usaha. Karakteristik peternak sapi Bali di Kecamatan Bongomeme Kabupaten Gorontalo disajikan pada tabel 1 berikut ini.

Tabel 1. Karakteristik Peternakan Sapi Bali DiKecamatan Bongomeme Kabupaten Gorontalo

\begin{tabular}{|c|c|c|c|}
\hline No. & Umumr (Tahun) & JumlahReponden (Orang) & $\begin{array}{c}\text { Prosentase } \\
(\%)\end{array}$ \\
\hline \multirow[t]{3}{*}{1} & $<15$ & 0 & 0 \\
\hline & $15-64$ & 13 & 92,86 \\
\hline & $>64$ & 1 & 7,14 \\
\hline \multirow[t]{6}{*}{2} & Jenjang Pendidikan & & \\
\hline & TidakSekolah & 0 & 0,00 \\
\hline & Tamat SD & 6 & 42,86 \\
\hline & Tamat SMP & 7 & 50,00 \\
\hline & Tamat SMU & 1 & 7,14 \\
\hline & Perguruan Tinggi & 0 & 0,00 \\
\hline \multirow[t]{4}{*}{3} & PengalamanBeternak & JumlahReponden (Orang) & $\begin{array}{c}\text { Prosentase } \\
(\%)\end{array}$ \\
\hline & $<5$ Tahun & 3 & 21,43 \\
\hline & 5 - 10 Tahun & 3 & 21,43 \\
\hline & $>10$ & 8 & 57,14 \\
\hline
\end{tabular}

Sumber : Hasil Olahan Data Primer, 2019

Rataan umur peternak yang memelihara sapi di Kecamatan Bongomeme Kabupaten Gorontalo merupakan umur produktif dalam menjalankan usahanya dimana umur produktif adalah 15-64 tahun. Peternak yang memiliki umur produktif umumnya mempunyai kemampuan fisik dan berfikir yang lebih baik dalam hal 
menghadapi dan menerima perubahan, inovasi dan adopsi dalam menjalankan usahanya bila dibandingkan dengan umur yang lebih tua.

Faktor penentukan keberhasilan dari usaha, adalah pengalaman peternak Pengalaman beternak sapi bali dapat dilihat pada tabel 1. Pengalaman beternak adalah pengalaman dalam mengelola usaha ternak. Pengalaman beternak dari peternak yang ada di kecamatan Bongomeme adalah adalah 5-10 tahun.

$$
\text { Menurut Adiwilaga (2004), }
$$

menyatakan bahwa peternak yang berada pada usia produktif akan lebih efektif dalam mengelola usahanya bila dibandingkan dengan peternak yang lebih tua. Tingkat pendidikan peternak sapi bali dikecamatan Bongomeme adalah SD sebanyak 6 orang atau sebesar $42,86 \%$, SMP sebanyak 7 orang atau sebesar 50,00 \%dan SMU sebanyak 1 orang sebesar 7,14\% hal ini menunjukkan bahwa Peternak Sapi Bali tingkat pendidikannya masih tergolong rendah dimana tingkat Pendidikan Petrenak Sapi bali rata rata tingkat pendidikannya SMP sebanyak 7 orang atau sebesar 50,00 \%. Rendahnya jenjang pendidikan ini akan berpengaruh baik terhadap kemampuan peternak dalam mengelola usaha yang dijalankan, terutama sikap terhadap inovasi usaha dimasa datang. Tingkat pendidikan memiliki hubungan yang cukup kuat (positif dan nyata) dengan efektifitas komunikasi. Semakin tinggi tingkat pendidikan maka komunikasi yang terjadi semakin efektif (Saidah, 2008). Dalam pemasaran diperlukan komunikasi yang bagus, baik kepada pelanggan maupun kepada pemasok. Dewi (2013) bahwa semakin baik pendidikan, semakin banyak pengalaman dalam menjalankan usaha, dan semakin mendukung lingkungan wirausaha dari seseorang akan berbanding lurus dengan keberhasilan usaha yang dijalani. Hal ini sesuai pendapat Soekartawi (2005) yang menyatakan bahwa rendahnya pendidikan pekerja merupakan kendala dalam menyerapi nformasi baru, khususnya yang berkaitan dengan proses difusi-inovasi teknologi. Handoko (2005), yang menyatakan bahwa pengalaman merupakan suatu faktor yang mempengaruhi kemampuan seseorang dalam menjalankan usahanya.

\section{Karateristik Pedagang Pengumpul}

Umur sangat berpengaruh langsung terhadap produktivitas tenaga kerja, semakin bertambah umur seseorang maka tenaga kerja yang dimiliki semakin produktif dan setelah pada batas umur tertentu produktivitasnya semakin menurun, umur tentunya akan berdampak pada kemampuan fisik seseorang dalam bertindak dan berusaha.

Untuk mengetahui karakteristik responden pedagang Pengumpul Sapi Bali dari segi umur, dapat dilihat pada Tabel 2.

Tabel 2. Umur Respoden Pedangang Pengumpul Di Pasar Tradisional Bongomeme Kabupaten Gorontalo

\begin{tabular}{cccc}
\hline Uo. & Jumlah Responden (Orang) & Presentase(\%) & 0 \\
\hline$<15$ & 41 & 08 \\
$15-64$ & 1 & 2 \\
\hline Jumlah & 44 & 42 & 100,00 \\
\hline
\end{tabular}

Sumber : Hasil Olahan Data Primer, 2019

Berdasarkan Tabel 2 dapat dilihat dari segi umur pedagang pengumpul sapi bali di pasar tradisional Bongomeme antara 15-64 tahun dan digolongkan pada usia yang produktif. Hal ini menunjukkan bahwa usia produktif dapat menunjang kelancaran dalam proses kegiatan berdagang dari perdagang pengumpu sapi bali di Pasar Bongomeme. Sejalan dengan Lasaharu (2020) peternak yang memelihara sapi dikecamatan Taluditi Kab. Pohuwato memiliki umur produktif yakni berumur 3062 tahun dalam usaha berdagang. 
Tingkat pendidikan dapat usaha pedangang sapi bali di pasar menunjang dalam peningkatan usaha, Bongomeme dapat dilihat pada tabel 3 sehingga akan berdampak pada kemajuan berikut.

Tabel 3. Tingkat Pendidikan Respoden Pedangang pengumpul Di Pasar Tradisi Bongomeme Kabupaten Gorontalo

\begin{tabular}{clccc}
\hline No & & Jenjang Pendidikan & Jumlah Responden Orang) & Presentase (\%) \\
\hline 1 & Tidak Sekolah & 0 & 0,00 \\
2 & Tamat SD & 37 & 88,10 \\
3 & Tamat SMP & 5 & 11,90 \\
4 & Tamat SMU & Jumlah & 0 & 0,00 \\
\hline & & \multirow{2}{*}{ ton }
\end{tabular}

Sumber : Hasil Olahan Data Primer, 2019

Tabel 3. Dapat dilihat untuk jenjang pendidikan, umumnya responden pedagang pengumpul sapi bali, berada pada ketegori pendidikan SD-SMP. Hal ini menunjukkan bahwa tingkat Pendidikan pedangang pengumpul masih rendah sehingga perlu adanya perhatian yang serius terkait dengan adanya peningkatan Pendidikan pedangang pengumpul. Hal ini sesuai pendapat Soekartawi (2005) yang menyatakan bahwa rendahnya pendidikan pekerja merupakan kendala dalam menyerapi nformasi baru, khususnya yang berkaitan dengan proses difusi-inovasi teknologi.

\section{Saluran Pemasaran}

Kegiatan usaha pedagang lokal yaitu melakukan pembelian ternak sapi dari peternak kemudian menjualnya ke pasar hewan. Konsumen dalam hal ini masyarakat umum yang datang membeli langsung ternak ke pasar hewan maupun pedagang pemotong yang pembelian ternak sapi di pasar hewan kemudian memotong ternak sapi tersebut di RPH setempat atau melakukan pemotongan sendiri.. Saluran pemasaran umumnya terbentuk secara alami, dari penelitian menunjukkan bahwa terdapat beberapa tingkatan lembaga pemasaran yaitu dimulai dari peternak sapi potong, pedagang pengumpul dan pedagang pengecer, aktivitas pemasaran ternak sapi potong di pasar tradisional Bongomeme dijalankan melalui beberapa tipe saluran pemasaran yaitu:

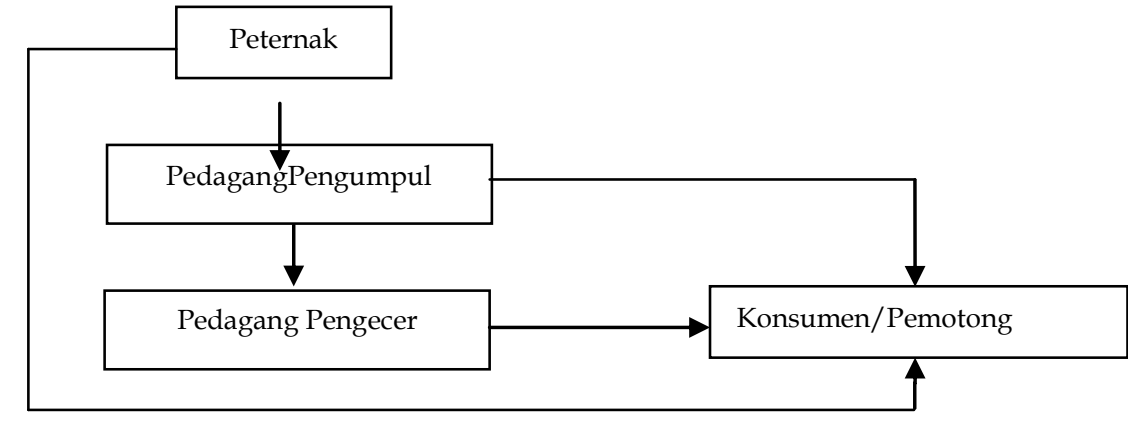

Gambar 1. Saluran Pemasaran Ternak Sapi pada Pasar Tradisional Bongomeme

Berdasarkan gambar dapat dilihat bahwa saluran pemasaran ternak sapi potong di pasar tradisional Bongomeme terdapat tiga jenis saluran pemasaran ternak sapi yaitu:

\section{Saluran I: Peternak - Konsumen (P-K)}

Saluran Pertama adalah tipe saluran yang sederhana, dimana petani eternak langsung berhubungan dengan pasar atau konsumen tanpa perantara. Tipe ini hanya terjadi sewaktu-waktu saja yaitu mana kala petani peternak membutuhkan sesuatu untuk kebutuhan hidupnya

Saluran II: Peternak-Pedagang LokalKonsumen (P-Pl-K) 
Saluran kedua adalah tipe saluran pemasaran yang terdapat pada pasar tradisional Bongomeme. Tipe saluran pemasaran inipetani peternak menjual langsung kepada pedagang pengumpul, dan para pedagang tersebut selanjutnya menjual kembali ternak sapi kepada konsumen/pemotong. Sejalan dengan penelitian yang dilakukan oleh Lasaharu (2020) tentang analisis pemasaran sapi potong di Kecamatan Taluditi Kabupaten Gorontalo mengemukakan bahwa Pola saluran pemasaran II yang ada di Kecamatan Taluditi yaitu saluran pemasaran 1 adalah Peternak-Pedagang Pengumpul- konsumen

\section{Saluran III: Peternak-Pedagang Pengumpul-Pedagang Pengecer-} Konsumen (P-Pp-Pc-K).

Saluran ketiga adalah tipe saluran pemasaran yang terdapat pada pasaran tradisional Bongomeme. Pada tipe saluran pemasaran III ini dimana petani peternak menjual langsung kepada pedagang Pengumpul, kemudian pedagang pengumpul menjual ternak kepada pedagang pengecer, dan para pedagang pengecer tersebut selanjutnya menjual ternak sapi kepada konsumen/pemotong dalam bentuk hidup. Sejalan dengan penelitian yang dilakukan oleh Lasaharu (2020) tentang analisis pemasaran sapi potong di Kecamatan Taluditi Kabupaten Gorontalo mengemukakan bahwa Pola saluran pemasaran III yang ada di Kecamatan Taluditi yaitu saluran saluran pemasaran : peternak-pedagang pengumpul-Pedagang pengecer-konsumen.

\section{Margin Pemasaran}

Setiap lembaga pemasaran berusaha untuk mendapatkan keuntungan dari kegiatan usahanya dalam pemasaran ternak sapi potong. Kegiatan usaha yang dilakukan adalah untuk meningkatkan tambahan nilai guna dari ternak sapi potong. Pedagang sapi berusaha menndapatkan tambahan nilai dengan mendistribusikan ternak sapi dari tempat petani peternak ke pasar hewan, dari satu pasar ke pasar lain atau kedaerah lain. Margin pemasaran pada setiap lembaga pemasaran dalam saluran pemasaran ternak sapi bali pada pasar tradisional Bongomeme dapat dilihat pada Tabel 4 .

Tabel 4. Margin Pada Saluran I Sapi Bali pada Pasar tradisional Bongomeme

\begin{tabular}{|c|c|c|}
\hline \multirow{2}{*}{ Lembaga Pemasaran } & \multicolumn{2}{|c|}{ Saluran I } \\
\hline & Nilai Rata-Rata (Rp/Ekor) & Presentase (\%) \\
\hline \multicolumn{3}{|l|}{ Peternak } \\
\hline a. Harga Jual & $10,500,000$ & \\
\hline \multicolumn{3}{|l|}{ b. BiayaPemasaran } \\
\hline - $\quad$ Biaya Tenaga Kerja & 24,342 & 25 \\
\hline - $\quad$ BiayaTransportasi & 48,684 & 50 \\
\hline - $\quad$ BiayaRestribusi & 24,342 & 25 \\
\hline \multicolumn{3}{|l|}{ Konsumen Akhir } \\
\hline Harga Beli & $10,500,000$ & 100 \\
\hline Margin Pemasaran & - & \\
\hline
\end{tabular}

Berdasarkan tabel 4, Menunjukan bahwa saluran pemasaran terdiri dari peternak langsung menjual ke konsumen. Pada saluran ini tidak memiliki margin karena peternak langsung memasarkan kepada konsumen. Dengan perhitungan biaya tenaga kerja Rp.24,342/orang, biaya transportasi Rp48,684/ekor, dan biaya restribusi Rp.24.342/bln. Pada saluran pemasaran II dan III memiliki margin lebih banyak dengan jumlah Rp.1,000,000, dan
500,000 karena hanya melalui lembaga pemasaran yaitu lembaga pemasaran yang terdiri dari peternak, pedagang pengumpul, pedangang pengecer dan konsumen. Ratarata jumlah ternak yang dijual dalam periodese banyak 2 ekor ternak. Deskripsi margin pemsaran saluran sapi bali di pasar tradisional Bongomeme Kabupaten Gorontalo disajikan pada tabel 5.

Tabel 5, menunjukan bahwa saluran II lembaga pemasaran yang menyalurkan 
sapi bali terdiri dari peternak, pedagang pengumpul, konsumen akhir. Total margin keseluruhan yaitu Rp.1,000,000. Perhitungan tenaga kerja untuk pedagang pengumpul Rp.70,455/orang, biaya transportasi Rp.140,909/ekor, dan biaya distribusi Rp70,455/bln. Jumlah ternak yang dijual dalam mingguan rata-rata sebanyak 3 ekor sapi.

Tabel 5. Margin Pada Saluran II Sapi Bali pada Pasar Lokal Bongomeme

\begin{tabular}{|c|c|c|c|}
\hline \multirow{2}{*}{\multicolumn{2}{|c|}{ Lembaga Pemasaran }} & \multicolumn{2}{|c|}{ SaluranII } \\
\hline & & Nilai Rata-Rata (Rp/Ekor) & Presentase (\%) \\
\hline \multicolumn{4}{|c|}{ Peternak } \\
\hline & arga Jual & $10,500,000$ & \\
\hline \multicolumn{4}{|c|}{ b. BiayaPemasaran } \\
\hline & - $\quad$ Biaya Tenaga Kerja & 24,342 & 25 \\
\hline & - $\quad$ BiayaTransportasi & 48,684 & 50 \\
\hline & - $\quad$ BiayaRestribusi & 24,342 & 25 \\
\hline \multicolumn{4}{|c|}{ PedagangPengumpul } \\
\hline a. & Harga Beli & $10,500,000$ & \\
\hline \multicolumn{4}{|c|}{ b. BiayaPemasaran } \\
\hline & - Biaya Tenaga Kerja & 70,455 & 25 \\
\hline & - $\quad$ BiayaTransportasi & 140,909 & 50 \\
\hline & - $\quad$ BiayaRestribusi & 70,455 & 25 \\
\hline c. & Harga Jual & $11,000,000$ & \\
\hline \multicolumn{4}{|c|}{ Konsumen Akhir } \\
\hline $\mathrm{Ha}$ & a Beli & $11,500,000$ & 100 \\
\hline Ma & gin Pemasaran & $1,000,000$ & \\
\hline
\end{tabular}

Tabel 6. Margin Pada SaluranIII Sapi Bali pada Pasar LokalBongomeme

\begin{tabular}{|c|c|c|}
\hline \multirow{2}{*}{ Lembaga Pemasaran } & \multicolumn{2}{|c|}{ Saluran III } \\
\hline & Nilai Rata-Rata (Rp/Ekor) & Presentase $(\%)$ \\
\hline \multicolumn{3}{|l|}{ Peternak } \\
\hline a. Harga Jual & $10,500,000$ & \\
\hline \multicolumn{3}{|l|}{ b. BiayaPemasaran } \\
\hline - Biaya Tenaga Kerja & 24,342 & 25 \\
\hline - BiayaTransportasi & 48,684 & 50 \\
\hline - BiayaRestribusi & 24,342 & 25 \\
\hline \multicolumn{3}{|l|}{ PedagangPengumpul } \\
\hline a. Harga Beli & $10,500,000$ & \\
\hline \multicolumn{3}{|l|}{ b. BiayaPemasaran } \\
\hline - Biaya Tenaga Kerja & 70,455 & 25 \\
\hline - $\quad$ BiayaTransportasi & 140,909 & 50 \\
\hline - BiayaRestribusi & 70,455 & 25 \\
\hline c. Harga Jual & $11,000,000$ & \\
\hline \multicolumn{3}{|l|}{ PedagangPengecer } \\
\hline a. Harga Beli & $11,000,000$ & \\
\hline \multicolumn{3}{|l|}{ b. BiayaPemasaran } \\
\hline - Biaya Tenaga Kerja & 65,000 & 22 \\
\hline - $\quad$ BiayaTransportasi & 169,000 & 56 \\
\hline - BiayaRestribusi & 65,000 & 22 \\
\hline c. Harga Jual & $11,500,000$ & \\
\hline \multicolumn{3}{|l|}{ Konsumen Akhir } \\
\hline Harga Beli & $11,500,000$ & 100 \\
\hline Margin Pemasaran & 500,000 & \\
\hline
\end{tabular}

Tabel 6, menunjukan bahwa saluran III lembaga pemasaran yang menyalurkan sapi bali adalah peternak, pedagang pengumpul, dan pengecer. Total margin keseluruhan yaitu Rp.500,000., Jumlah ternak yang dijual setiap minggu rata-rata sebanyak 2 ekor sapi. Dengan perhitungan tenaga kerja untuk pedagang pengumpul Rp. 65,000/orang, transportasi Rp.140,909/ekor, dan retribusi $\mathrm{Rp}$ 141 
$\begin{array}{lcr}70,455 / \text { bln. } & \text { Pedagang } & \text { pengecer } \\ \text { perhitungannya: } & \text { tenaga } & \text { kerja } \\ \text { Rp.65,000/orang, } & \text { transportasi } & \text { Rp. }\end{array}$ 169,000/ekor, dan retribusi Rp65,000/bln. Perbedaan harga biaya pemasaran yang dikeluarkan oleh pedagang pengumpul, pedagang pengecer dipengaruhi oleh biaya yang di keluarkan. Total margin yang di peroleh dari saluran II lebih besar dibandingkan dari saluran III.

Berdasarkan tabel margin pemasaran pada peternak, pedagang pengumpul, diatas dapat dilihat perbedaan pada saluran pemasaran dipengaruhi oleh beberapa factor diantaranya lembaga yang

\section{DAFTAR PUSTAKA}

Adiwilaga. 2004. Ilmu usaha tani. Bandung: Alumni.

Afifah, 2014. Unnes Physics Education Journal, 2014, 6-11.

Antara, Made. 2009, Pertanian, Bangkit dan Bangkrut?. Arti Foundation. Denpasar

Badan Pusat Statistik, 2019. Kecamatan Bongomeme Dalam Angka. BPS Kabupaten Gorontalo

Daniel, Moehar. 2002. Pengantar Ekonomi Pertanian. Jakarta: PT. BuniAksara.

Daymon, C., Holloway, I. 2008. MetodeMetode Riset Kualitatif dalam Public Relations And Marketing Communications. Penerjemah Wiratama, C. PenerbitBentang. Yogyakarta.

Dermawan, R. (2018). Analysis Feasibility of Effort Breeding Laying Hens. Jambura Journal of Animal Science, 1(1), 25-39.

Hanafiah A.M dan Saefuddin, A.M, 2010. Tataniaga Hasil Peternakan. Edisi Kedua. Universitas Indonesia Press. Jakarta terlibat dan besarnya yang dikeluarkan oleh suatu lembaga pemasaran.

\section{KESIMPULAN}

Saluran pemasaran sapi Bali di pasar tradisional Bongomeme Kabupaten Gorontalo terdapat 3 pola saluran pemasaran yaitu: (1) Peternak-konsumen., (2) Peternak-Pedagang pengumpulkonsumen, dan (3) Peternak-Pedagang pengumpul-peng ecer-konsumen. Margin pemasaran disetiap lembaga pemasaran yaitu terbesar pada saluran II adalah pedangang pengumul sebesar Rp.1.000.000/ekor, dan saluran III adalah Pengecer sebesar Rp.500.000/ekor

Hernanto F. 1989. Ilmu Usahatani. Jakarta. Penebar Swadaya

Lasaharu, N. A., \& Boekoesoe, Y. (2020). Analisis Pemasaran SapiPotong. Jambura Journal of Animal Science, 2(2), 62-75.

Mandaka, S., dan M.P. Hutagaol. 2005. Analisis fungsi keuntungan, efisiensi ekonomi dan kemungkinan skema kredit bagi pengembangan skala usaha peternakan sapi perah rakyat di Kelurahan Kebon Pedes Kota Bogor. JAE. Vol. 23 (2): 191-209.

Napitupulu, A. H. 2009. Tataniaga Peternakan: Suatu Pengantar Sistem, Koordinasi dan Pasar Berjangka. Jurusan Sosial Ekonomi Peternakan, Fakultas Peternakan Institut Pertanian Bogor, Bogor.

Saragih, Bungaran. 2008. Agribisnis, Paradigma Baru Pembanguan Ekonomi Berbasis Pertanian. Yayasan Mulia Persada, Jakarta: PT Surveyor Indonesia dan PSP LP-IPB.

Soeharjo, A dan Patong. 2007. Sendi - Sendi Pokok Usaha tani. Jurusan Ilmu Sosial Ekonomi Pertanian. Institut Pertanian Bogor : Bogor 
Soekartawi. 20011. Ilmu Usaha tani dan Penelitian Pengembangan Petani Kecil .UI Press, Jakarta

Sudarmono, A.S dan Y. S. Bambang.. 2008. Sapi Potong Pemeliharaan, Perbaikan Produksi, Prospek Bisnis, Analisis Penggemukan. Penebar Swadaya, Jakarta

Sukanata I W., Suciani, I G.N. Kayana., I W. Budiartha. 2010. Kajian Kritis terhadap Penerapan Kebijakan Kuota
Perdagangan dan Efisiensi Pemasaran Sapi Potong Antar Pulau. Laporan Akhir Penelitian. Fakultas Peternakan Universitas Udayana. Denpasar

Yapanto, L. M. (2020). Tataniaga Dan Margin Pemasaran Ikan Tuna Di Kota Gorontalo. Jambura Journal of Animal Science, 2(2), 38-45. 